\title{
PERKEMBANGAN DESA WISATA KREBET DAN DAMPAKNYA TERHADAP KONDISI EKONOMI MASYARAKAT DUSUN KREBET, DESA SENDANGSARI, KECAMATAN PAJANGAN, KABUPATEN BANTUL
}

\author{
Rosyida Rahmawati, Joni Purwohandoyo \\ Program Studi Pembangunan Wilayah, Fakultas Geografi, Universitas Gadjah Mada \\ Bulaksumur, Depok, Sleman, D.I.Yogyakarta 55281, Indonesia \\ E-mail: rosyidarahmawati12@gmail.com
}

\begin{abstract}
Abstrak
Desa Wisata Krebet memiliki simbol utama kerajinan batik kayu. Ada dampak ekonomi yang dirasakan masyarakat Dusun Krebet sejak menjadi desa wisata, yaitu dampak langsung, dampak tidak langsung, dampak lanjutan, maupun efek pengganda dari kegiatan wisata. Penelitian ini bertujuan mengidentifikasi perkembangan Desa Wisata Krebet, menganalisis efek pengganda dari adanya perkembangan Desa Wisata Krebet, dan menganalisis keterkaitan antara perkembangan Desa Wisata Krebet dengan dampak ekonomi yang ditimbulkan. Analisis data dilakukan dengan cara analisis deskriptif, analisis dampak ekonomi kegiatan pariwisata, dan analisis efek pengganda. Hasil penelitian menunjukkan bahwa perkembangan Desa Wisata Krebet yang dilihat dari empat aspek perkembangan desa wisata, saling berhubungan dengan dampak ekonomi yang ditimbulkan. Namun, dampak langsung yang berasal dari kegiatan non wisata lebih tinggi dibandingkan dengan dampak langsung yang berasal dari wisatawan. Hal ini menunjukkan bahwa usaha di Desa Wisata Krebet akan tetap berjalan meskipun wisatawan yang berkunjung ke Desa Wisata Krebet mengalami kenaikan atau penurunan jumlah kunjungan karena produk kerajinan batik kayu dapat dipasarkan keluar Desa Wisata Krebet. Adanya branding "Desa Wisata Krebet" juga akan membantu pemasaran produk kerajinan batik kayu di luar Desa Wisata Krebet.
\end{abstract}

Kata kunci: Perkembangan Desa Wisata, Dampak Ekonomi, Multiplier Effect.

\begin{abstract}
The icon of Krebet Tourism Village is wooden batik craft. There is an economic impact felt by the community of Krebet Hamlet since becoming a tourism village, there are direct impacts, indirect impacts, induced impacts and multiplier effects of tourism activities in Krebet Tourism Village. This research aims to identify the development of the Krebet Tourism Village, analyzing the multiplier effects of the development of the Krebet Tourism Village, and analyzing the linkages between the development of the Krebet Tourism Village and the economic impacts. Data analysis done by descriptive analysis, analysis of the economic impact of tourism activities, and analysis of multiplier effects. The results of the research indicate that the development of the Krebet Tourism Village which is viewed from four aspects of rural tourism development, were related to economic impact. However, the direct impact from non-tourism activities was higher than the direct impact from tourists. This shows that businesses in the Krebet Tourism Village will continue to run even though tourists who visited Krebet Tourism Village either increased or decreased because the wooden batik craft products can be marketed outside Krebet Tourism Village.The branding of "Krebet Tourism Village" will also help the marketing of wooden batik craft products outside Krebet Tourism Village.
\end{abstract}

Key words: The development of Tourism Village, Economic Impacts, Multiplier Effect. 


\section{PENDAHULUAN}

Pariwisata merupakan sektor unggulan (leading sector) yang menjadi salah satu kunci penting untuk pembangunan wilayah di suatu negara, pendorong pertumbuhan ekonomi, dan peningkatan kesejahteraan masyarakat (UNWTO, 1981 dalam Rencana Strategis Pengembangan Destinasi dan Industri Pariwisata 2015 2019). Hal ini sesuai dengan poin Sustainable Development Goals (SDGs) nomor delapan yaitu Decent Work and Economic Growth, yang memiliki target untuk mempromosikan pertumbuhan ekonomi yang berkelanjutan dan melaksanakan kebijakan untuk promosi pariwisata dan budaya lokal berkelanjutan.

Tren perkembangan pariwisata saat ini adalah mengarah ke alternative tourism atau wisata minat khusus dengan skala kecil yang sifatnya adalah pembelajaran dan melatih skill. Salah satu destinasi wisata minat khusus yang dapat dikunjungi oleh wisatawan adalah desa wisata. Desa wisata adalah suatu bentuk integrasi antara atraksi, akomodasi dan fasilitas pendukung yang disajikan dalam suatu struktur kehidupan masyarakat yang menyatu dengan tata cara dan tradisi yang berlaku (Nuryanti, 1993).

Penelitian ini dilakukan di Desa Wisata Krebet, Kecamatan Pajangan, Kabupaten Bantul. Icon utama dari Desa Wisata Krebet adalah kerajinan batik kayunya. Dampak adalah setiap perubahan yang terjadi dalam lingkungan akibat adanya aktivitas manusia (Suratmo, 2004). Teori multiplier effect menyatakan bahwa suatu kegiatan akan dapat memacu timbulnya kegiatan lain (Glasson, 1990). Teori Multiplier Effect berkaitan dengan pengembangan perekonomian suatu daerah. Makin banyak kegiatan yang timbul, makin tinggi pula dinamisasi suatu wilayah yang pada akhirnya akan meningkatkan pengembangan wilayah.
Multiplier effect adalah suatu keterkaitan langsung dan tidak langsung yang kemudian mendorong adanya kegiatan pembangunan diakibatkan oleh kegiatan pada bidang tertentu baik bersifat positif ataupun negatif yang menggerakan kegiatan di bidang-bidang lain (Lestari, 2015). Dampak pengganda mengacu pada income atau pendapatan yang berasal dari pengeluaran wisatawan di lokasi wisata. Berdasarkan Marine Ecotourism for Atlantic Area (META) (2001), dampak ekonomi terhadap masyarakat lokal dapat diukur menggunakan tiga tipe pengganda, yaitu:

a. Keynesian Local Income Multiplier, yaitu nilai yang diperoleh dari dampak langsung atas pengeluaran wisatawan.

b. Ratio Income Multiplier Tipe I, yaitu nilai yang yang diperoleh dari dampak tidak langsung atas pengeluaran wisatawan.

c. Ratio Income Multiplier Tipe II, yaitu nilai yang yang diperoleh dari dampak lanjutan.

\section{METODE PENELITIAN}

Penelitian dilakukan menggunakan metode survey yaitu dengan pengumpulan data primer meliputi observasi, wawancara menggunakan kuesioner, dan wawancara mendalam (indepth interview). Data sekunder dikumpulkan dengan melakukan pengumpulan data terkait profil Dusun Krebet atau Desa Wisata Krebet dan kondisi Desa Sendangsari.

Metode pengambilan sampel dilakukan dengan menggunakan teknik non probability sampling, yaitu purposive sampling. Non probability sampling adalah teknik pengambilan sampel yang tidak memberikan peluang yang sama bagi setiap unsur (anggota) populasi untuk dipilih menjadi anggota sampel. Purposive sampling dipilih karena tidak semua masyarakat Desa Wisata Krebet menjadi sampel penelitian, hanya masyarakat yang terlibat di dalam usaha pariwisata yaitu seluruh pemilik sanggar kerajinan batik kayu, pemilik homestay, pemilik usaha kuliner, 
dan tenaga kerja pada masing-masing unit usaha.

Metode pengambilan sampel untuk tenaga kerja yang bekerja di masing-masing unit usaha dilakukan dengan menggunakan teknik probability sampling, yaitu simple random sampling. Simple random sampling dipilih karena pengambilan anggota sampel dari populasi dilakukan secara acak tanpa memperhatikan strata dalam populasi tersebut (Sugiyono, 2016). Jumlah populasi tenaga kerja yang bekerja di sanggar kerajinan batik kayu adalah 166 tenaga kerja. Toleransi kesalahan (error tolerance) yang diambil pada penelitian ini adalah sebesar $5 \%(0,05)$, sehingga jumlah sampelnya adalah 117 tenaga kerja.

Analisis data dilakukan berdasarkan pada masing-masing tujuan penelitian. Tujuan pertama yaitu mengidentifikasi perkembangan Desa Wisata Krebet dari awal terbentuk hingga saat ini, dilakukan dengan analisis deskriptif yang digunakan untuk mendeskripsikan atau menggambarkan kumpulan data berdasarkan hasil pengamatan dilapangan.

Tujuan kedua, menganalisis efek pengganda (multiplier effect) ekonomi dari adanya perkembangan Desa Wisata Krebet dilakukan dengan menggunakan analisis dampak ekonomi kegiatan pariwisata dan analisis efek pengganda (multiplier effect). Dampak ekonomi pariwisata dapat dibedakan menjadi tiga yaitu dampak langsung, tidak langsung, dan lanjutan (Tribe, 2011). Kemudian dari dampak ekonomi tersebut dapat dihitung nilai multiplier effectnya.

Tujuan ketiga, menganalisis keterkaitan antara perkembangan Desa Wisata Krebet dengan dampak ekonomi yang ditimbulkan dilakukan dengan menggunakan hasil dari tujuan pertama dan tujuan kedua pada penelitian ini. Dimana hasil dari tujuan pertama yaitu analisis secara deskriptif mengenai perkembangan Desa Wisata Krebet dan hasil dari tujuan kedua yaitu nilai efek pengganda (multiplier effect) yang di dalamnya mencakup nilai dampak langsung, tidak langsung, dan lanjutan dari perkembangan Desa Wisata Krebet. Keterkaitan antara perkembangan Desa Wisata Krebet dan dampak ekonomi dijelaskan secara deskriptif analisis.

\section{HASIL DAN PEMBAHASAN}

\section{Perkembangan Desa Wisata Krebet}

Kerajinan batik kayu di Dusun Krebet mulai muncul sejak tahun 1970, namun pada saat itu Desa Wisata Krebet belum terbentuk. Pada saat itu mayoritas masyarakat Dusun Krebet bekerja sebagai buruh, peternak, dan petani palawija seperti ketela, jagung, kedelai, dan kacang tanah. Kemudian seiring berjalannya waktu, mulai banyak masyarakat yang tertarik untuk membuat kerajinan batik kayu sehingga profesi masyarakat yang awalnya adalah buruh, petani, ataupun peternak mulai berkurang.

Generasi penerus dari para petani dan peternak banyak yang tidak melanjutkan profesi orang tuanya dan lebih tertarik pada kerajinan batik kayu. Hal ini karena kerajinan batik kayu lebih menjanjikan dibandingkan dengan pekerjaan tersebut. Para orang tua tetap melanjutkan profesinya sebagai petani dan peternak, namun anak-anaknya jarang yang mengikuti jejak para orang tuanya sehingga saat ini sebagian besar masyarakat Dusun Krebet berprofesi sebagai perajin batik kayu.

Desa Wisata Krebet mengalami berbagai macam perubahan, mulai dari awal terbentuk hingga saat ini. Perkembangan Desa Wisata Krebet dapat diidentifikasi melalui 4 (empat) aspek yaitu aspek kualitas pelayanan (service quality), fasilitas (facilities), manajemen desa (village management), dan hasil pariwisata (tourism 
outcomes) (Park dan Yoon, 2011). Aspek tersebut merupakan aspek pembangunan praktis yang dapat digunakan untuk mengukur pembangunan desa wisata yang berkelanjutan (Sustainable Rural Tourism Development).

Tabel 1. Perkembangan Desa Wisata Krebet dari Aspek Kualitas Pelayanan dan Aspek

Fasilitas

\begin{tabular}{|c|c|c|c|c|c|c|c|c|c|c|c|c|}
\hline \multirow[b]{2}{*}{ Tahun } & \multicolumn{6}{|c|}{$\begin{array}{c}\text { Keberadaan dan Jumlah Indikator dari Aspek Kualitas Pelayanan di } \\
\text { Desa Wisata Krebet }\end{array}$} & \multicolumn{6}{|c|}{$\begin{array}{c}\text { Keberadaan dan Jumlah Indikator dari Aspek Fasilitas di Desa } \\
\text { Wisata Krebet }\end{array}$} \\
\hline & $\begin{array}{c}\text { Paket } \\
\text { Wisata }\end{array}$ & $\begin{array}{c}\text { Potensi } \\
\text { Alam }\end{array}$ & $\begin{array}{l}\text { Potensi } \\
\text { Budaya }\end{array}$ & $\begin{array}{l}\text { Potensi } \\
\text { Buatan }\end{array}$ & $\begin{array}{l}\text { Pemandu } \\
\text { Wisata } \\
\text { dan } \\
\text { Instruktur } \\
\text { Kegiatan }\end{array}$ & Aksesibilitas & $\begin{array}{l}\text { Tempat } \\
\text { Parkir* }\end{array}$ & $\begin{array}{l}\text { Toilet } \\
\text { Umum* }\end{array}$ & $\begin{array}{l}\text { Tempat } \\
\text { Ibadah }\end{array}$ & $\begin{array}{l}\text { Warung } \\
\text { Makan }\end{array}$ & Homestay & $\begin{array}{l}\text { Amphi } \\
\text { Theater }\end{array}$ \\
\hline $\begin{array}{c}1970- \\
2000\end{array}$ & - & 4 & 11 & 44 & - & Jalan Berbatu & - & - & 2 & - & - & - \\
\hline $2001-$ & - & 4 & 11 & 44 & - & Jalan Aspal & 1 & - & 3 & - & - & - \\
\hline 2014 & - & 4 & 12 & 44 & 30 & Jalan Aspal & 1 & 2 & 3 & 1 & - & - \\
\hline 2015 & - & 4 & 12 & 45 & 30 & Jalan Aspal & 1 & 2 & 3 & 2 & 12 & - \\
\hline 2016 & - & 4 & 12 & 45 & 30 & Jalan Aspal & 1 & 2 & 3 & 4 & 25 & 1 \\
\hline 2017 & 16 & 4 & 12 & 45 & 43 & Jalan Aspal & 1 & 2 & 3 & 7 & 33 & 1 \\
\hline 2018 & 16 & 4 & 12 & 45 & 43 & Jalan Aspal & 1 & 2 & 3 & 7 & 33 & 1 \\
\hline
\end{tabular}

Sumber: Data Primer, 2018.

${ }^{*}$ ): Lokasi yang disediakan fleksibel, namun di depan Sekretariat Desa Wisata Krebet terdapat 1 lahan parkir dan 2 toilet umum.

Berdasarkan Tabel 1, perkembangan Desa Wisata Krebet dari aspek kualitas pelayanan (service quality) dan aspek fasilitas (facilities) dapat dilihat dari tahun 1970 hingga 2018. Kualitas pelayanan (service quality) merupakan usaha memberikan pelayanan agar tercapainya keinginan atau harapan pelanggan (Normasari, 2013).

Tahun 1970 merupakan tahun dimana mulai munculnya kerajinan batik kayu di Dusun Krebet. Potensi alam di Desa Wisata Krebet merupakan potensi alami sehingga sejak tahun 1970 bahkan sebelum tahun 1970 hingga saat ini sudah ada. Potensi budaya merupakan potensi yang masih dilestarikan di Desa Wisata Krebet dan menjadi hal penting untuk mencerminkan suatu desa wisata karena desa wisata sangat erat kaitannya dengan adat istiadat dan kebudayaan lokal.

Potensi buatan di Desa Wisata Krebet meliputi sanggar batik kayu, outbound, dan jelajah desa. Jumlah sanggar batik kayu terus bertambah hingga tahun 2018 mencapai 43 sanggar kerajinan batik kayu. Seluruh potensi wisata di Desa Wisata Krebet tersebut dikemas dalam paket wisata yang disediakan oleh pengelola Desa Wisata Krebet sejak tahun 2017 lalu. Selain itu, dengan adanya pemandu wisata dan instruktur kegiatan pembatikan batik kayu di Desa Wisata Krebet yang mulai terbentuk tahun 2014 dan adanya akses jalan yang semakin baik sejak diresmikannya Desa Wisata Krebet tahun 2002, maka kualitas pelayanan di Desa Wisata Krebet saat ini semakin baik.

Aspek fasilitas (facilities) merupakan hal penting yang diperlukan wisatawan selama berada di daerah tujuan wisata. Fasilitas yang disediakan oleh pengelola Desa Wisata Krebet bagi wisatawan yang berkunjung antara lain adalah fasilitas umum yang meliputi tempat parkir, toilet umum, tempat ibadah, warung makan, penginapan (homestay), dan amphi theater. Fasilitas yang tersedia di Desa Wisata Krebet semakin bertambah dari tahun ke tahun. Hal ini menunjukkan bahwa Desa Wisata Krebet semakin berkembang dan semakin siap dalam mengelola desa 
wisatanya.

Manajemen desa (village management) termasuk aspek penting dalam mengidentifikasi perkembangan desa wisata. Desa wisata yang memiliki pengelolaan atau manajemen yang baik mencerminkan bahwa desa wisata tersebut memiliki kerjasama yang baik antar masyarakat dalam mengelola desa wisata tersebut. Aspek manajemen desa meliputi lembaga masyarakat di Desa Wisata Krebet dan kemitraan Desa Wisata Krebet dengan lembaga/instansi/pemerintah di luar Dusun Krebet. Aspek hasil pariwisata (tourism outcomes) di Desa Wisata Krebet dapat dilihat melalui beberapa indikator, yaitu jumlah pemilik usaha kerajinan batik kayu di Desa Wisata Krebet, karakteristik usaha kerajinan batik kayu di Desa Wisata Krebet, cara penjualan produk kerajinan batik kayu, karakteristik tenaga kerja di sanggar kerajinan batik kayu, jumlah kunjungan wisatawan, serta prestasi yang diraih oleh Desa Wisata Krebet. Secara garis besar perkembangan Desa Wisata Krebet dari aspek manajemen desa (village management) dan aspek hasil pariwisata (tourism outcomes) dapat dilihat pada Tabel 2 berikut.

Tabel 2. Perkembangan Desa Wisata Krebet dari Aspek Manajemen Desa dan Aspek Hasil Pariwisata

\begin{tabular}{|c|c|c|c|c|c|c|c|c|c|c|c|c|c|c|c|c|c|c|c|c|}
\hline \multirow{3}{*}{ Tahun } & \multicolumn{8}{|c|}{$\begin{array}{c}\text { Keberadaan dan Jumlah Indikator dari Aspek Manajemen Desa di Desa } \\
\text { Wisata Krebet }\end{array}$} & \multicolumn{12}{|c|}{$\begin{array}{l}\text { Keberadaan dan Jumlah Indikator dari Aspek Hasil Pariwisata di Desa } \\
\text { Wisata Krebet }\end{array}$} \\
\hline & \multicolumn{5}{|c|}{ Lembaga Masyarakat } & \multicolumn{3}{|c|}{ Kemitraan di luar Krebet } & \multirow[b]{2}{*}{$\begin{array}{c}\text { Pemilik } \\
\text { Usaha } \\
\text { Batik } \\
\text { Kayu }\end{array}$} & \multicolumn{4}{|c|}{$\begin{array}{c}\text { Karaktetistik Usaha } \\
\text { Batik Kayu }^{(1)}\end{array}$} & \multicolumn{4}{|c|}{$\begin{array}{c}\text { Cara Penjualan } \\
\text { Produk( }^{(2)}\end{array}$} & & \multirow[b]{2}{*}{$\begin{array}{l}\text { Tenaga } \\
\text { Kerja }\end{array}$} & \multirow[b]{2}{*}{$\begin{array}{l}\text { Kun- } \\
\text { jungnn } \\
\text { Wisata }\end{array}$} \\
\hline & $\begin{array}{c}\text { Pok- } \\
\text { darwis } \\
\text { Krebet }\end{array}$ & $\begin{array}{c}\text { Pengelola } \\
\text { Desa } \\
\text { Wisata } \\
\text { Krebet }\end{array}$ & $\begin{array}{l}\text { Kope- } \\
\text { rasi } \\
\text { Sido } \\
\text { Katon }\end{array}$ & $\begin{array}{l}\text { LPMD } \\
\text { Dusun } \\
\text { Krebet }\end{array}$ & $\begin{array}{c}\text { Karang } \\
\text { Taruna } \\
\text { Unit } \\
\text { Krebet }\end{array}$ & $\begin{array}{l}\text { Peme- } \\
\text { rintah }\end{array}$ & Swasta & $\begin{array}{l}\text { LSM/ } \\
\text { PT/ } \\
\text { Lainnya }\end{array}$ & & A & B & C & D & A & B & C & D & E & & \\
\hline 1970 & & & & & & & & & & & & & & & & & & & & \\
\hline- & 1 & - & - & - & - & - & - & - & 17 & 9 & 2 & 6 & 0 & 9 & 0 & 1 & 2 & 5 & 49 & - \\
\hline $\begin{array}{l}2001 \\
- \\
2013\end{array}$ & 1 & 1 & 1 & 1 & 1 & 4 & - & - & 42 & 17 & 15 & 8 & 2 & 21 & 3 & 4 & 5 & 9 & 108 & - \\
\hline 2014 & 1 & 1 & 1 & 1 & 1 & - & - & - & 42 & 17 & 15 & 8 & 2 & 21 & 3 & 4 & 5 & 9 & 112 & 28.855 \\
\hline 2015 & 1 & 1 & 1 & 1 & 1 & - & - & - & 43 & 17 & 16 & 8 & 2 & 22 & 3 & 4 & 5 & 9 & 129 & 32.614 \\
\hline 2016 & 1 & 1 & 1 & 1 & 1 & 2 & - & - & 43 & 17 & 16 & 8 & 2 & 22 & 3 & 4 & 5 & 9 & 147 & 36.347 \\
\hline 2017 & 1 & 1 & 1 & 1 & 1 & 1 & 1 & 1 & 43 & 17 & 16 & 8 & 2 & 22 & 3 & 4 & 5 & 9 & 162 & 37.190 \\
\hline 2018 & 1 & 1 & 1 & 1 & 1 & 1 & - & - & 43 & 17 & 16 & 8 & 2 & 22 & 3 & 4 & 5 & 9 & 166 & $1.502^{*}$ \\
\hline
\end{tabular}

Sumber: Data Primer, 2018.

Keterangan:

(*) Jumlah Kunjungan Khusus Edukasi Batik Kayu hingga April 2018.

(1) a. Produksi Lengkap

b. Khusus Pembatikan

c. Putihan (Setengah Jadi)

d. Non-batik Kayu

(2) a. Langsung ke Konsumen

b. Melalui Perantara

c. Langsung ke Konsumen dan Melalui Perantara

d. Diambil oleh Distributor

e. Langsung ke Konsumen dan Diambil oleh Distributor

Berdasarkan Tabel 2, perkembangan Desa Wisata Krebet dari aspek manajemen desa (village management) dan aspek hasil pariwisata (tourism outcomes) dapat dilihat dari tahun 1970 hingga 2018. Aspek manajemen desa (village management) terbagi menjadi dua yaitu lembaga masyarakat di Desa Wisata Krebet dan kemitraan di luar Desa Wisata Krebet. Saat ini Desa Wisata Krebet memiliki lima lembaga masyarakat dan telah menjalin kemitraan dengan beberapa instansi/ 


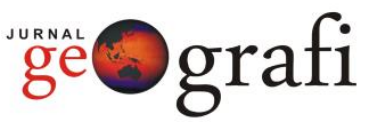

lembaga yang dapat menunjang kegiatan di Desa Wisata Krebet. Bentuk kemitraan yang pernah dilakukan di Desa Wisata Krebet antara lain adalah berupa bantuan dana, bantuan pengadaan alat produksi kerajinan, pelatihan dan pendampingan bagi perajin dan pelaku usaha, bantuan fasilitas seperti WiFi, amphi theater, serta bantuan infrastruktur berupa perbaikan akses jalan.

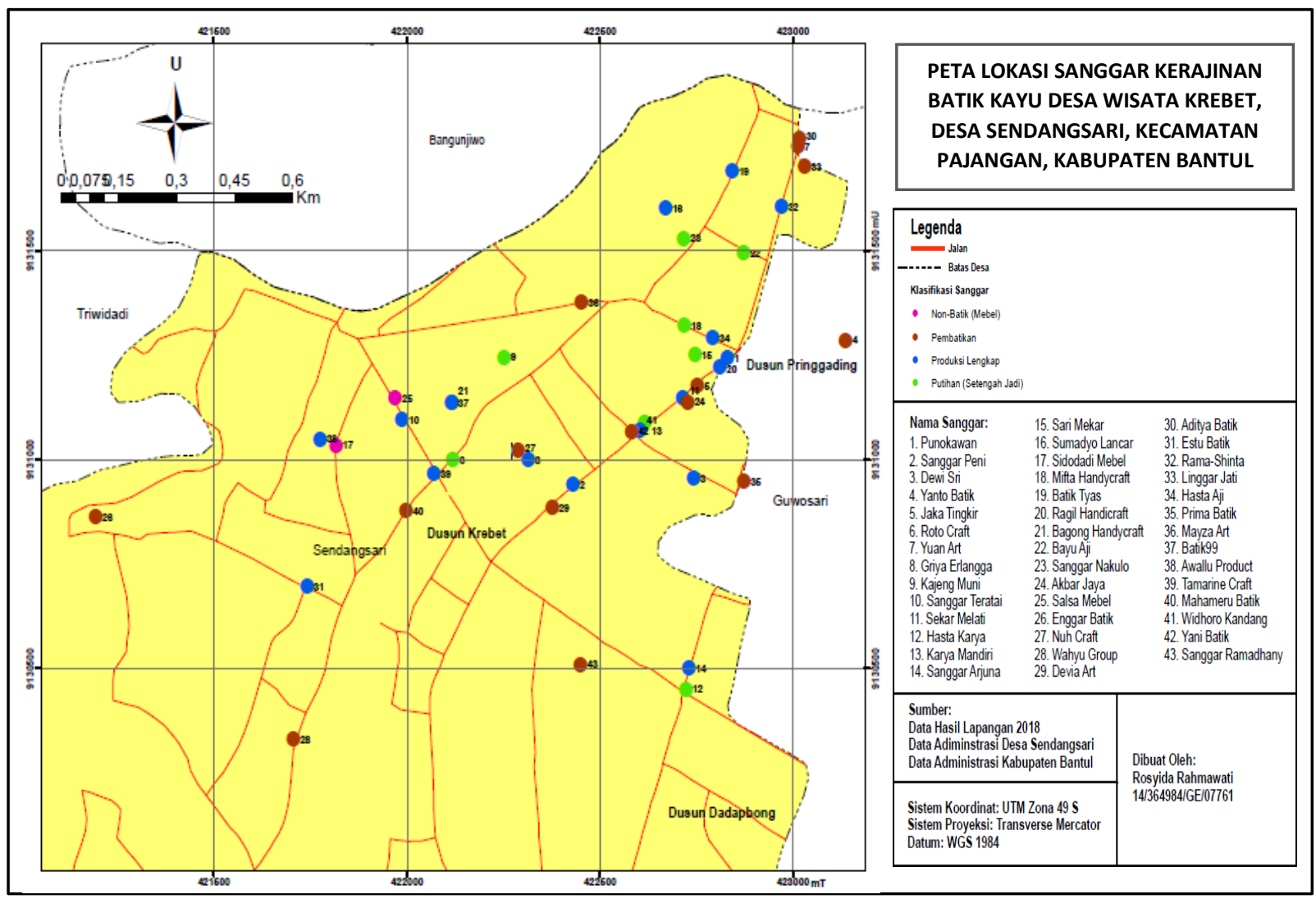

Gambar 1. Peta Lokasi Sanggar Kerajinan Batik Kayu Desa Wisata Krebet

Tahun 1970 merupakan tahun munculnya kerajinan batik kayu di Dusun Krebet. Berdasarkan Gambar 1., jumlah pemilik usaha batik kayu terus bertambah hingga tahun 2018 mencapai 43 sanggar kerajinan batik kayu dengan berbagai macam karakteristik, cara penjualan produk, dan jumlah tenaga kerja yang dimiliki. Seiring bertambahnya sanggar kerajinan batik kayu di Desa Wisata Krebet, jumlah tenaga kerja pun meningkat. Hingga saat ini tenaga kerja aktif di Desa Wisata Krebet berjumlah 166 tenaga kerja. Selain itu, Jumlah keseluruhan kunjungan wisatawan, termasuk kunjungan rombongan yang tercatat oleh pengelola Desa Wisata Krebet dalam kurun waktu tiga tahun (2014 - 2017) lalu terjadi peningkatan

sebanyak

800-3700 pengunjung setiap tahunnya. Namun, di tahun 2018 data yang masih tercatat hingga bulan April adalah sebanyak 1.502 pengunjung. Data terakhir yang tercatat merupakan data kunjungan rombongan wisata edukasi batik kayu, belum termasuk data keseluruhan kunjungan wisatawan di Desa Wisata Krebet.

Tahun 2013 Desa Wisata Krebet memperoleh penghargaan sebagai desa wisata kategori tumbuh dan berkembang tingkat Kabupaten Bantul dan Provinsi Daerah Istimewa Yogyakarta. Dua tahun terakhir yaitu tahun 2017 dan 2018 Desa Wisata Krebet berhasil meraih penghargaan sebagai desa wisata kategori maju tingkat Kabupaten Bantul secara berturut-turut. 
Hal ini menunjukkan bahwa Desa Wisata Krebet mengalami perkembangan yang cukup pesat dan berhasil mengelola desanya sebagai desa wisata.

\section{Dampak Ekonomi Kegiatan Wisata}

Kegiatan di Desa Wisata Krebet dapat memberikan dampak positif bagi masyarakat sekitar Dusun Krebet, salah satunya adalah dampak ekonomi. Dampak ekonomi kegiatan wisata dapat diklasifikasikan menjadi tiga jenis, yaitu dampak langsung (direct impact), dampak tidak langsung (indirect impact), dan dampak lanjutan (induced impact) (Vanhove, 2005 dalam Mutty, 2015).
Dampak ekonomi langsung (direct impact) merupakan manfaat langsung yang dirasakan oleh pelaku usaha di Desa Wisata Krebet dari adanya pengeluaran yang dilakukan oleh wisatawan yang berkunjung di Desa Wisata Krebet. Namun, dampak langsung yang dirasakan oleh pelaku usaha dapat pula dihitung dari kegiatan non wisata (pemasaran produk secara mandiri). Pelaku usaha yang terkena dampak ekonomi langsung dari adanya kegiatan wisata maupun non wisata adalah pemilik usaha yang berada di Desa Wisata Krebet, yaitu pemilik usaha sanggar kerajinan batik kayu, pemilik homestay, dan penyedia kuliner.

Tabel 3. Dampak Ekonomi Langsung di Desa Wisata Krebet

\begin{tabular}{|c|c|c|c|c|c|c|}
\hline \multirow{2}{*}{ Jenis unit usaha } & \multirow{2}{*}{$\begin{array}{l}\text { Responden } \\
\text { unit usaha } \\
\text { (b) }\end{array}$} & \multirow{2}{*}{$\begin{array}{l}\text { Jumlah } \\
\text { unit } \\
\text { usaha (c) }\end{array}$} & \multicolumn{2}{|c|}{$\begin{array}{l}\text { Rata-rata pendapatan per } \\
\text { bulan }(\mathrm{d})\end{array}$} & \multicolumn{2}{|c|}{$\begin{array}{l}\text { Dampak ekonomi langsung } \\
\left(\mathrm{e}=\mathrm{c}^{*} \mathrm{~d}\right)\end{array}$} \\
\hline & & & Wisatawan & $\begin{array}{c}\text { Non } \\
\text { Wisatawan }\end{array}$ & Wisatawan & $\begin{array}{c}\text { Non } \\
\text { Wisatawan }\end{array}$ \\
\hline $\begin{array}{l}\text { Sanggar batik kayu } \\
\text { (lengkap) }\end{array}$ & 17 & 17 & 4.765 .883 & 14.111.177 & 81.020 .000 & 239.890 .000 \\
\hline $\begin{array}{l}\text { Sanggar batik kayu } \\
\text { (pembatikan) }\end{array}$ & 16 & 16 & 575.000 & 4.134 .375 & 9.200 .000 & 66.150 .000 \\
\hline $\begin{array}{l}\text { Sanggar batik kayu } \\
\text { (putihan) }\end{array}$ & 8 & 8 & 137.500 & 4.300 .000 & 1.100 .000 & 34.400 .000 \\
\hline $\begin{array}{l}\text { Sanggar non-batik } \\
\text { kayu (mebel) }\end{array}$ & 2 & 2 & 0 & 5.500 .000 & 0 & 11.000 .000 \\
\hline Homestay & 33 & 33 & 164.849 & 0 & 5.440 .000 & 0 \\
\hline Kuliner & 8 & 8 & 125.000 & 0 & 1.000 .000 & 0 \\
\hline $\begin{array}{l}\text { Total Penerimaan } \\
\text { Unit Usaha }\end{array}$ & 84 & 84 & 5.768 .232 & 28.045 .552 & 97.760 .000 & 351.440 .000 \\
\hline
\end{tabular}

Sumber: Data Primer, 2018.

Berdasarkan Tabel 3, pendapatan unit usaha setiap bulannya terbagi menjadi dua yaitu pendapatan yang berasal dari pengeluaran wisatawan di lokasi Desa Wisata Krebet dan pendapatan kegiatan non wisata (pemasaran produk secara mandiri). Dampak langsung (direct impact) yang berasal dari kegiatan non wisata lebih tinggi apabila dibandingkan dengan dampak langsung (direct impact) yang berasal dari wisatawan karena pendapatan yang diterima oleh unit usaha, terutama unit usaha sanggar kerajinan batik kayu maupun sanggar non batik kayu (mebel) berasal dari barang-barang yang sifatnya dapat dipasarkan atau diekspor keluar Desa Wisata Krebet. Hanya dua unit usaha homestay dan kuliner yang tidak memiliki pendapatan dari kegiatan non wisata. Kedua unit usaha tersebut merupakan unit usaha yang hanya dapat beroperasi di Desa Wisata Krebet dan bergantung pada wisatawan yang berkunjung ke Desa Wisata Krebet, sehingga tidak ada pendapatan yang berasal dari kegiatan non wisata untuk kedua unit usaha tersebut.

Dampak ekonomi tidak langsung (indirect impact) merupakan hasil dari pengeluaran unit usaha yang ada di lokasi Desa Wisata Krebet berupa biaya bahan 
baku produksi, biaya pemeliharaan alat

biaya transportasi. produksi, biaya untuk gaji tenaga kerja, dan

Tabel 4. Dampak Ekonomi Tidak Langsung di Desa Wisata Krebet

\begin{tabular}{|c|c|c|c|c|c|c|}
\hline Keterangan & $\begin{array}{c}\text { Sanggar } \\
\text { batik kayu } \\
\text { (lengkap) }\end{array}$ & $\begin{array}{c}\text { Sanggar batik } \\
\text { kayu } \\
\text { (pembatikan) }\end{array}$ & $\begin{array}{c}\text { Sanggar } \\
\text { batik kayu } \\
\text { (putihan) }\end{array}$ & $\begin{array}{c}\text { Sanggar non } \\
\text { batik kayu } \\
\text { (mebel) }\end{array}$ & Homestay & Kuliner \\
\hline $\begin{array}{l}\text { (1) Rata-rata } \\
\text { pengeluaran di dalam } \\
\text { Desa Wisata Krebet }\end{array}$ & & & & & & \\
\hline Biaya bahan baku & 8.288 .236 & 1.250 .000 & 1.937 .500 & 3.000 .000 & 0 & 1.250 .000 \\
\hline Biaya pemeliharaan alat & 60.942 & 25.000 & 31.250 & 50.000 & 0 & 0 \\
\hline Jumlah (a) & 8.349 .178 & 1.275 .000 & 1.968 .750 & 3.050 .000 & 0 & 1.250 .000 \\
\hline Jumlah unit usaha (b) & 17 & 16 & 8 & 2 & 33 & 8 \\
\hline $\begin{array}{l}\text { Total pengeluaran di } \\
\text { dalam Desa Wisata } \\
\text { Krebet }\left(c=a^{*} b\right)\end{array}$ & 141.936 .026 & 20.400 .000 & 15.750 .000 & 6.100 .000 & 0 & 10.000 .000 \\
\hline $\begin{array}{l}\text { (2) Rata-rata } \\
\text { pengeluaran di luar } \\
\text { Desa Wisata Krebet }\end{array}$ & & & & & & \\
\hline Biaya transportasi & 400.000 & 195.313 & 206.250 & 300.000 & 0 & 62.500 \\
\hline Jumlah (d) & 400.000 & 195.313 & 206.250 & 300.000 & 0 & 62.500 \\
\hline $\begin{array}{l}\text { Total pengeluaran di } \\
\text { luar Desa Wisata Krebet } \\
\left(e=b^{*} d\right)\end{array}$ & 6.800 .000 & 3.125 .000 & 1.650 .000 & 600.000 & 0 & 500.000 \\
\hline
\end{tabular}

Sumber: Data Primer, 2018.

Berdasarkan Tabel 4, dampak ekonomi tidak langsung (indirect impact) tertinggi adalah pada unit usaha sanggar batik kayu produksi lengkap, sedangkan dampak ekonomi tidak langsung terendah adalah pada unit usaha homestay. Hal tersebut terjadi karena unit usaha homestay tidak memiliki tenaga kerja dan tidak mengeluarkan biaya untuk bahan baku dan pemeliharaan alat untuk produksi setiap bulannya, sedangkan unit usaha sanggar batik kayu produksi lengkap harus mengeluarkan biaya bahan baku, biaya pemeliharaan alat, dan biaya tenaga kerja setiap bulannya untuk mendukung proses produksi kerajinan batik kayu di Desa Wisata Krebet.

Nilai dampak tidak langsung (indirect impact) berkaitan pula dengan dampak langsung (direct impact). Apabila unit usaha di Desa Wisata Krebet mendapatkan permintaan produk kerajinan yang banyak dari konsumen, maka biaya untuk bahan baku produksi, biaya pemeliharaan alat produksi, dan biaya untuk gaji tenaga kerja yang bekerja di masing-masing unit usaha semakin meningkat pula, disamping mendapat omset yang tinggi dari penjualan produk kerajinan batik kayu tersebut. Apabila pengeluaran untuk ketiga biaya tersebut semakin meningkat, maka nilai dampak tidak langsung (indirect impact) di Desa Wisata Krebet akan semakin meningkat pula.

Dampak yang ditimbulkan dari adanya aktivitas dan perkembangan Desa Wisata Krebet selain dampak langsung (direct impact) dan dampak tidak langsung (indirect impact) adalah dampak lanjutan (induced impact). Dampak lanjutan (induced impact) merupakan pengeluaran yang dilakukan oleh tenaga kerja di sekitar Desa Wisata Krebet. Dampak lanjutan ini merupakan lanjutan dari pendapatan yang telah diperoleh tenaga kerja di unit usaha di Desa Wisata Krebet tempat mereka bekerja. Tenaga kerja membelanjakan pendapatan yang diperoleh setiap bulannya dari unit usaha tempat mereka bekerja. Dampak 
lanjutan (induced impact) yang dihitung adalah pengeluaran tenaga kerja yang dilakukan di lokasi Desa Wisata Krebet, antara lain biaya untuk konsumsi seharihari, biaya kebutuhan sekolah anak, dan biaya lainnya. Perhitungan tersebut digunakan untuk mengetahui pendapatan yang diperoleh sektor lain namun masih berada di dalam Desa Wisata Krebet agar perputaran ekonomi dan efek pengganda (multiplier effect) dari adanya Desa Wisata Krebet dapat diketahui.

Tabel 5. Dampak Ekonomi Lanjutan di Desa Wisata Krebet

\begin{tabular}{lcccc}
\hline \multicolumn{1}{c}{ Tenaga Kerja } & $\begin{array}{c}\text { Jumlah } \\
\text { Populasi } \\
\text { Tenaga } \\
\text { Kerja (a) }\end{array}$ & $\begin{array}{c}\text { Rata-rata } \\
\text { pengeluaran } \\
\text { tenaga kerja } \\
\text { (Rp) (b) }\end{array}$ & $\begin{array}{c}\text { Proporsi } \\
\text { Pengeluaran di } \\
\text { Desa Wisata } \\
\text { Krebet (\%) (c) }\end{array}$ & $\begin{array}{c}\text { Dampak } \\
\text { Ekonomi } \\
\text { Lanjutan (Rp) } \\
\left(\mathbf{d}=\mathbf{a}^{*} \mathbf{b}^{*} \mathbf{c}\right)\end{array}$ \\
\hline $\begin{array}{l}\text { Sanggar batik kayu } \\
\text { (lengkap) }\end{array}$ & 96 & 991.667 & 0,568 & 54.073 .618 \\
$\begin{array}{l}\text { Sanggar batik kayu } \\
\text { (pembatikan) }\end{array}$ & 52 & 941.458 & 0,586 & 28.688 .108 \\
$\begin{array}{l}\text { Sanggar batik kayu } \\
\text { (putihan) }\end{array}$ & 13 & 1.055 .000 & 0,645 & 8.846 .175 \\
$\begin{array}{l}\text { Sanggar non-batik kayu } \\
\text { (mebel) }\end{array}$ & 5 & 1.627 .000 & 0,842 & 6.849 .670 \\
$\begin{array}{l}\text { Homestay } \\
\text { Kuliner }\end{array}$ & 0 & 0 & 0,000 & 0 \\
\hline Total & 0 & 0 & 0,000 & 0 \\
\hline
\end{tabular}

Sumber: Data Primer, 2018.

Berdasarkan Tabel 5, proporsi pengeluaran di dalam Desa Wisata Krebet meliputi pengeluaran untuk biaya konsumsi sehari-hari bagi tenaga kerja yang berasal dari dalam Desa Wisata Krebet, biaya sekolah bagi yang bersekolah di dalam Dusun Krebet, dan biaya kebutuhan lainnya. Sedangkan pengeluaran di luar Desa Wisata Krebet meliputi pengeluaran untuk biaya konsumsi sehari-hari bagi tenaga kerja yang berasal dari luar Desa Wisata Krebet, biaya sekolah, biaya listrik, biaya telepon, biaya air, biaya transportasi, dan biaya kebutuhan lainnya. Tenaga kerja di dalam Desa Wisata Krebet tidak mengeluarkan semua biaya kebutuhan di dalam Desa Wisata Krebet saja, melainkan mengeluarkan kebutuhan di luar Desa Wisata Krebet pula seperti biaya listrik, biaya telepon, biaya air, biaya transportasi, biaya sekolah bagi yang bersekolah di luar Dusun Krebet, dan biaya kebutuhan lainnya.
Rata-rata total pengeluaran tenaga kerja dan proporsi pengeluaran di Desa Wisata Krebet terbesar adalah oleh tenaga kerja yang bekerja di sanggar non batik kayu (mebel), sedangkan rata-rata total pengeluaran tenaga kerja dan proporsi pengeluaran di Desa Wisata Krebet terkecil adalah unit usaha homestay dan kuliner karena kedua unit usaha tersebut tidak memiliki tenaga kerja. Namun, dampak ekonomi lanjutan (induced impact) terbesar adalah pada pengeluaran tenaga kerja yang bekerja di sanggar batik kayu produksi lengkap, sedangkan dampak ekonomi lanjutan (induced impact) terendah adalah pada pengeluaran tenaga kerja yang bekerja di sanggar non batik kayu (mebel). Hal ini terjadi karena jumlah populasi tenaga kerja yang bekerja di sanggar batik kayu produksi lengkap jauh lebih banyak dibandingkan dengan jumlah populasi tenaga kerja yang bekerja di sanggar non batik kayu (mebel). 
Dampak ekonomi lanjutan (induced impact) berkaitan dengan dampak langsung (direct impact) dan dampak tidak langsung (indirect impact). Apabila unit usaha di Desa Wisata Krebet mendapatkan permintaan produk kerajinan yang banyak dari konsumen, maka biaya untuk bahan baku produksi, biaya pemeliharaan alat produksi, dan biaya untuk gaji tenaga kerja yang bekerja di masing-masing unit usaha semakin meningkat pula. Apabila ketiga biaya tersebut semakin meningkat, maka maka nilai dampak tidak langsung (indirect impact) di Desa Wisata Krebet akan semakin meningkat pula. Apabila tenaga kerja mendapatkan penghasilan yang tinggi maka pengeluaran yang akan dilakukan untuk kebutuhan sehari-hari di Desa Wisata Krebet akan sebanding dengan penghasilan yang diterima dan nilai dampak lanjutan (induced impact) akan semakin meningkat.
Efek pengganda (multiplier effect) digunakan untuk mengukur dampak ekonomi terhadap masyarakat di sekitar lokasi Desa Wisata Krebet yang dapat diukur menggunakan tiga tipe pengganda (META, 2001 dalam Mutty, 2015) yaitu (1) Keynesian Local Income Multiplier, yaitu nilai yang diperoleh dari dampak langsung atas pengeluaran wisatawan, (2) Ratio Income Multiplier Tipe I, yaitu nilai yang diperoleh dari dampak tidak langsung atas pengeluaran wisatawan, dan (3) Ratio Income Multiplier Tipe II, yaitu nilai yang diperoleh dari dampak lanjutan. Nilai efek pengganda (multiplier effect) yang dihitung hanya nilai yang berasal dari pengeluaran wisatawan di Desa Wisata Krebet, tidak termasuk kegiatan non wisata. Nilai efek pengganda (multiplier effect) dari dampak ekonomi di Desa Wisata Krebet dapat dilihat pada Tabel 6 berikut.

Tabel 6. Efek Pengganda Dari Arus Uang yang Terjadi di Desa Wisata Krebet

\begin{tabular}{ll}
\hline \multicolumn{1}{c}{ Multiplier } & Nilai \\
\hline Keynesian Local Income Multiplier & 81,31 \\
Ratio Income Multiplier Tipe I & 3,98 \\
Ratio Income Multiplier Tipe II & 4,99 \\
\hline
\end{tabular}

Sumber: Data Primer, 2018.

Nilai Keynesian Local Income Multiplier, Ratio Income Multiplier Tipe I, dan Ratio Income Multiplier Tipe II dipengaruhi oleh nilai dampak langsung (direct impact), dampak tidak langsung (indirect impact), dan dampak lanjutan (induced impact). Berdasarkan Tabel 6, nilai Keynesian Local Income Multiplier adalah sebesar 81,31, artinya bahwa setiap peningkatan satu rupiah pengeluaran yang dilakukan oleh wisatawan di Desa Wisata Krebet akan memiliki dampak terhadap ekonomi lokal sebesar 81,31 rupiah.

Nilai Keynesian Local Income Multiplier merupakan nilai multiplier tertinggi di antara nilai multiplier lainnya karena memperhitungkan seluruh nilai dampak ekonomi dan jumlah pengeluaran yang dilakukan oleh wisatawan di Desa Wisata Krebet. Apabila pengeluaran yang dilakukan oleh wisatawan di Desa Wisata Krebet semakin tinggi, maka seluruh nilai dampak ekonomi dan nilai Keynesian Local Income Multiplier, Ratio Income Multiplier Tipe I dan nilai Ratio Income Multiplier Tipe II akan semakin tinggi pula.

Nilai Ratio Income Multiplier Tipe I adalah sebesar 3,98, artinya bahwa setiap peningkatan satu rupiah pada penerimaan unit usaha di Desa Wisata Krebet akan mengakibatkan peningkatan sebesar 3,98 rupiah terhadap pendapatan unit usaha (direct impact) dan pendapatan tenaga kerja (indirect impact). Nilai Ratio Income Multiplier 
Tipe II adalah sebesar 4,99, artinya bahwa setiap peningkatan satu rupiah pada penerimaan unit usaha di Desa Wisata Krebet akan mengakibatkan peningkatan sebesar 4,99 rupiah pada pendapatan unit usaha (direct impact), pendapatan tenaga kerja (indirect impact), dan pengeluaran tenaga kerja (induced impact) dalam perputaran ekonomi lokal di sekitar Desa Wisata Krebet. Ketiga nilai efek pengganda (multiplier effect) tersebut berbanding lurus dengan pengeluaran yang dilakukan oleh wisatawan di Desa Wisata Krebet. Apabila pengeluaran yang dilakukan oleh wisatawan di Desa Wisata Krebet semakin tinggi, maka ketiga nilai efek pengganda (multiplier effect) tersebut akan semakin tinggi pula.

Nilai efek pengganda (multiplier effect) dapat ditingkatkan melalui pengembangan desa wisata seperti peningkatan kualitas produk kerajinan batik kayu, pelayanan, fasilitas, manajemen desa, serta promosi wisata yang masif melalui website dan media sosial, sehingga meningkatkan jumlah wisatawan yang berkunjung ke Desa Wisata Krebet dan meningkatkan pendapatan unit usaha dan pendapatan tanaga kerja. Berdasarkan Marine Ecotourism for Atlantic Area (META) (2001), apabila ketiga nilai multiplier tersebut lebih besar atau sama dengan satu $(\geq 1)$, maka secara keseluruhan lokasi wisata tersebut telah mampu memberikan dampak ekonomi terhadap kegiatan wisatanya. Hal ini menunjukkan bahwa perkembangan Desa Wisata Krebet membawa dampak ekonomi bagi masyarakat Desa Wisata Krebet dan sekitarnya baik dampak langsung (direct impact), dampak tidak langsung (indirect impact), dan dampak lanjutan (induced impact).

\section{Keterkaitan Antara Perkembangan Desa Wisata Krebet dengan Dampak Ekonomi yang Ditimbulkan}

Perkembangan Desa Wisata Krebet membawa dampak positif bagi masyarakat sekitar, terutama dalam bidang ekonomi. Kegiatan wisata yang terdapat di Desa Wisata Krebet dapat meningkatkan pendapatan masyarakat Desa Wisata Krebet dan membuka lapangan pekerjaan bagi masyarakat di sekitar Desa Wisata Krebet.

Perkembangan Desa Wisata Krebet yang dilihat dari empat aspek yaitu kualitas pelayanan (service quality), fasilitas (facilities), manajemen desa (village management), dan hasil pariwisata (tourism outcomes) secara keseluruhan menimbulkan dampak ekonomi kegiatan wisata yang dapat diukur melalui dampak langsung (direct impact), dampak tidak langsung (indirect impact), dan dampak lanjutan (induced impact). Ketiga dampak tersebut kemudian dapat digunakan untuk menganalisis nilai efek pengganda (multiplier effect) dari adanya perkembangan Desa Wisata Krebet.

Tabel 7. Hubungan Perkembangan Desa Wisata Krebet dengan Dampak Ekonomi yang Ditimbulkan

\begin{tabular}{|c|c|c|c|}
\hline $\begin{array}{c}\text { Aspek Perkembangan } \\
\text { Desa Wisata Krebet }\end{array}$ & Indikator & $\begin{array}{l}\text { Dampak } \\
\text { Ekonomi }\end{array}$ & Analisis Hubungan \\
\hline $\begin{array}{l}\text { Aspek Kualitas } \\
\text { Pelayanan } \\
\text { (ServiceQuality) }\end{array}$ & $\begin{array}{l}\text { Paket Wisata: } \\
\text { - Edukasi Batik Kayu } \\
\text { - Outbound } \\
\text { - Kuliner }\end{array}$ & \multirow{3}{*}{$\begin{array}{l}\text { Dampak } \\
\text { Langsung } \\
\text { (Direct Impact) }\end{array}$} & \multirow{3}{*}{$\begin{array}{l}\text { - Dampak langsung (direct impact) } \\
\text { dipengaruhi oleh tiga aspek dan beberapa } \\
\text { indikator perkembangan Desa Wisata } \\
\text { Krebet di dalamnya. } \\
\text { - Dampak langsung (direct impact) terbesar } \\
\text { berasal dari ketiga aspek tersebut karena } \\
\text { pengeluaran terbesar wisatawan di Desa } \\
\text { Wisata Krebet adalah pada aspek tersebut. } \\
\text { - Kegiatan non wisata memiliki nilai dampak }\end{array}$} \\
\hline $\begin{array}{l}\text { Aspek Fasilitas } \\
\text { (Facilities) }\end{array}$ & Homestay & & \\
\hline $\begin{array}{l}\text { Aspek Hasil Pariwisata } \\
\text { (Tourism Outcomes) }\end{array}$ & $\begin{array}{l}\text { Jumlah kunjungan } \\
\text { rombongan }\end{array}$ & & \\
\hline
\end{tabular}




\begin{tabular}{|c|c|c|c|}
\hline $\begin{array}{c}\text { Aspek Perkembangan } \\
\text { Desa Wisata Krebet }\end{array}$ & Indikator & $\begin{array}{l}\text { Dampak } \\
\text { Ekonomi }\end{array}$ & Analisis Hubungan \\
\hline & wisatawan & & $\begin{array}{l}\text { langsung yang lebih besar dibandingkan } \\
\text { dengan nilai dampak langsung yang berasal } \\
\text { dari kegiatan wisata karena sifat barang } \\
\text { yang dapat dipasarkan keluar Desa Wisata } \\
\text { Krebet. }\end{array}$ \\
\hline $\begin{array}{l}\text { Aspek Hasil } \\
\text { Pariwisata (Tourism } \\
\text { Outcomes) }\end{array}$ & $\begin{array}{l}\text { - Pemilik usaha di } \\
\text { Desa Wisata Krebet } \\
\text { - Jumlah kunjungan } \\
\text { rombongan } \\
\text { wisatawan }\end{array}$ & $\begin{array}{l}\text { Dampak Tidak } \\
\text { Langsung } \\
\text { (Indirect Impact) }\end{array}$ & $\begin{array}{l}\text { - Nilai dampak tidak langsung (indirect } \\
\text { impact) di Desa Wisata Krebet dipengaruhi } \\
\text { oleh besarnya pengeluaran yang dilakukan } \\
\text { oleh unit usaha. } \\
\text { - Dampak tidak langsung berbanding lurus } \\
\text { dengan dampak langsung (direct impact). }\end{array}$ \\
\hline $\begin{array}{l}\text { Aspek Hasil Pariwisata } \\
\text { (Tourism Outcomes) }\end{array}$ & $\begin{array}{l}\text { - Tenaga kerja pada } \\
\text { unit usaha di Desa } \\
\text { Wisata Krebet } \\
\text { - Jumlah kunjungan } \\
\text { rombongan } \\
\text { wisatawan }\end{array}$ & $\begin{array}{l}\text { Dampak } \\
\text { Lanjutan } \\
\text { (Induced } \\
\text { Impact) }\end{array}$ & $\begin{array}{l}\text { - Nilai lanjutan (inuced impact) di Desa Wisata } \\
\text { Krebet dipengaruhi oleh besarnya } \\
\text { pengeluaran yang dilakukan oleh tenaga } \\
\text { kerja di dalam Desa Wisata Krebet. } \\
\text { - Dampak lanjutan berbanding lurus dengan } \\
\text { dampak langsung (direct impact) dan } \\
\text { dampak tidak langsung (indirect impact). }\end{array}$ \\
\hline
\end{tabular}

Sumber: Analisis Peneliti, 2018.

Berdasarkan Tabel 7, aspek perkembangan Desa Wisata Krebet menimbulkan dampak ekonomi, mulai dari dampak langsung (direct impact), dampak tidak langsung (indirect impact), dan dampak lanjutan (induced impact). Dampak langsung (direct impact) di Desa Wisata Krebet terbagi menjadi dua, yaitu pendapatan yang berasal dari wisatawan dan pendapatan dari kegiatan non wisata (pemasaran produk secara mandiri). Dampak langsung (direct impact) yang berasal dari kegiatan non wisata lebih besar dari pada dampak langsung (direct impact) yang berasal dari wisatawan. Hal tersebut terjadi karena sifat barang yang dapat diekspor atau dipasarkan keluar Desa Wisata Krebet membuat pemasaran tidak hanya dilakukan di dalam Desa Wisata Krebet saja, tetapi dapat pula dilakukan di luar Desa Wisata Krebet, sehingga unit usaha di Desa Wisata Krebet terutama unit usaha kerajinan batik kayu dan non batik kayu (mebel) akan tetap berjalan meskipun wisatawan yang berkunjung ke Desa Wisata Krebet mengalami kenaikan atau penurunan jumlah kunjungan. Unit usaha kerajinan batik kayu di Desa Wisata Krebet justru akan terbantu oleh adanya branding "Desa Wisata Krebet" dalam pemasaran produk kerajinannya di luar Desa Wisata Krebet.

Namun, secara keseluruhan nilai dampak langsung (direct impact) yang berasal dari wisatawan, dampak tidak langsung (indirect impact), dan dampak lanjutan (induced impact) menimbulkan nilai efek pengganda (multiplier effect) lebih besar atau sama dengan satu $(\geq 1)$. Berdasarkan Marine Ecotourism for Atlantic Area (META) (2001), apabila ketiga nilai multiplier yang terdiri dari nilai Keynesian Local Income Multiplier, Ratio Income Multiplier Tipe I, dan Ratio Income Multiplier Tipe II lebih besar atau sama dengan satu $(\geq 1)$, maka secara keseluruhan lokasi wisata tersebut telah mampu memberikan dampak ekonomi terhadap kegiatan wisatanya. Hal ini menunjukkan bahwa perkembangan Desa Wisata Krebet membawa dampak ekonomi bagi masyarakat Desa Wisata Krebet dan sekitarnya baik dampak langsung (direct impact), dampak tidak langsung (indirect impact), dan dampak lanjutan (induced impact).

\section{KESIMPULAN}

Perkembangan Desa Wisata Krebet yang dilihat dari empat aspek perkembangan desa wisata yaitu aspek kualitas pelayanan (service quality), fasilitas 
(facilities), manajemen desa (village management), dan hasil pariwisata (tourism outcomes), secara keseluruhan saling berhubungan dengan dampak ekonomi yang ditimbulkan. Ketiga nilai multiplier (Keynesian Local Income Multiplier, Ratio Income Multiplier Tipe I, dan Ratio Income Multiplier Tipe II) yang ditimbulkan adalah lebih dari satu $(>1)$, artinya secara keseluruhan Desa Wisata Krebet telah mampu memberikan dampak ekonomi bagi kegiatan wisatanya.

Namun, apabila dilihat dari dampak langsung (direct impact) yang diperoleh unit usaha di Desa Wisata Krebet, terutama unit usaha kerajinan batik kayu, unit usaha tersebut memiliki dampak langsung (direct impact) yang lebih tinggi dari kegiatan non wisata dibandingkan dengan dampak langsung (direct impact) yang berasal dari wisatawan. Unit usaha di Desa Wisata Krebet akan tetap berjalan meskipun wisatawan yang berkunjung ke Desa Wisata Krebet mengalami kenaikan atau penurunan jumlah kunjungan karena produk kerajinan batik kayu dapat dipasarkan keluar Desa Wisata Krebet dan terbantu dengan adanya branding "Desa Wisata Krebet" sehingga pemasaran produk kerajinan batik kayu di luar Desa Wisata Krebet akan semakin mudah.

\section{UCAPAN TERIMA KASIH}

Ucapan terima kasih penulis masyarakat Desa Wisata Krebet yang telah memberikan bantuan kepada penulis selama melaksanakan penelitian ini. Terima kasih pula kepada rekan-rekan Prodi Pembangunan Wilayah, Fakultas Geografi Universitas Gadjah Mada yang telah bersedia membantu penulis selama kegiatan pengambilan data di lapangan.

\section{DAFTAR PUSTAKA}

Glasson, J. (1990). Pengantar Perencanaan Regional. Terjemahan Paul Sitohang.
Jakarta: Lembaga Penerbit Fakultas Ekonomi Universitas Indonesia.

Lestari, A. (2015). Analisis Multiplier Effect Ekonomi Perkebunan Kelapa Sawit di Kabupaten Mesuji. Skripsi Fakultas Ekonomi dan Bisnis Universitas Lampung. Lampung.

Marine Ecotourism for Atlantic Area (META). (2001). Planning for Marine Ecotourism in The EU Atlantic Area. Bristol: University of The West of England.

Mutty, D. (2015). Analisis Dampak Ekonomi Kegiatan Wisata Alam (Studi Kasus: Floating Market Lembang, Bandung). Skripsi Fakultas Ekonomi dan Manajemen Institut Pertanian Bogor. Bogor. $93 \mathrm{hlm}$.

Normasari, S. (2013). Pengaruh Kualitas Pelayanan Terhadap Kepuasan Pelanggan, Citra Perusahaan Dan Loyalitas Pelanggan Survei Padatamu Pelanggan Yang Menginap Di Hotel Pelangi Malang. Jurnal Administrasi Bisnis, 6(2).

Nuryanti, W. (1993). Concept, Perspective and Challenges, makalah bagian dari Laporan Konferensi Internasional mengenai Pariwisata Budaya. Yogyakarta: Gadjah Mada University Press.

Park, Duk-Byeong \& Yoon, Yoo-Shik. (2011). Developing Sustainable Rural Tourism Evaluation Indicators. International Journal of Tourism Research, 13, 401 - 415. DOI: $10.1002 /$ jtr.804.

Sugiyono. (2016). Metode Penelitian Kuantitatif, Kualitatif, dan R\&D. Bandung: Alfabeta.

Suratmo, F, Gunawan. (2004). Analisis Mengenai Dampak Lingkungan. Yogyakarta: Gadjah Mada University Press.

Tribe, J. (2011). The Economics of Recreation, Leisure and Tourism (4th ed.). Oxford: Elsevier. 
United Nations Development Programme and World Tourism Organization. (1981). Tourism Development Plan for Nusa Tenggara, Indonesia. Madrid: World Tourism Organization. pp: 69 vol 1. 